\title{
Princess Marina Hospital HIV rates:Interrupted time series analysis for policy review
}

\author{
Mooketsi Molefi* \\ Family Medicine \& Public Health, University of Botswana, Gaborone, Botswana
}

\section{Objective}

We aimed to assess the effect of the amended Public Health act of 2013 on facility-based HIV testing in Princess Marina Hospital

\section{Introduction}

HIV testing remains the mainstay of optimal HIV care and is pivotal to control and prevention of the disease, however efforts to attain optimal testing levels have been undermined by low HIV testing especially in developing countries. Botswana in response, amended its Public Health Act in September 2013 but the effect of this action on facility based HIV testing rates has not been evaluated

\section{Methods}

We carried out an effect assessment using interrupted time-series analysis method, where we accessed electronic medical records of patients seen in Princess Marina Hospital from June 2011 to May 2015. Rates were developed from the proportion of patients that tested each month out of the number that registered, and that figure used that as our data point in the series. September 2013 served as our intervention period in the series. We ran the (i) crude and (ii) sexstratified model regression models in stata ${ }^{\circledR}$ yielding Newey-West coefficients with their $95 \%$ confidence intervals. Graphical display of the models were also produced to visual appreciation and inspection

\section{Results}

Two hundred and twenty-nine thousand six hundred and ninety two patients were registered between June 2011 and May 2015. Of those tested the significant majority being females $(65 \%)$. From the Newey-regression output there was no significant change in the level of HIV testing immediately after the intervention however there was a change in trend $(\mathrm{p}=0.002)$ post the intervention. Stratification by gender, revealed no statistically significant difference between males and females, either in the levels nor the trend post intervention compared to pre-intervention

\section{Conclusions}

The amendment of the Public Health act of 2013, has brought about trend change in HIV testing however there has not been any apparent difference in the levels nor trends on HIV testing between males and females. Nationwide health facility-based studies could assist assess the overall effect of the amended act on HIV testing rates

\section{Keywords}

HIV testing rates; Interrupted time series analysis; public health act; Princess Marina Hospital

\section{Acknowledgments}

I would like to express my sincere gratitude to the Afya-Bora Consortium, Primary mentors and site mentors, Botswana-Upenn Partnership, University of Botswana (Faculty of Medicine), Ministry of Health (Leadership, HRDC Data Management Unit), Princess Marina Hospital and the

Gaborone District Health Management Team

\section{References}

1. Provider Initiated HIV Testing and Counseling: One Day Training Programme, Field Test Version. WHO Guidelines Approved by the Guidelines Review Committee. Geneva2011.

2. Donnell D, Baeten JM, Kiarie J, Thomas KK, Stevens W, Cohen $\mathrm{CR}$, et al. Heterosexual HIV-1 transmission after initiation of antiretroviral therapy: a prospective cohort analysis. The Lancet. 2010;375(9731):2092-8.

3. Lawn SD, Harries AD, Anglaret X, Myer L, Wood R. Early mortality among adults accessing antiretroviral treatment programmes in subSaharan Africa. Aids. 2008;22(15):1897-908.

4. McMahon JM, Pouget ER, Tortu S, Volpe EM, Torres L, Rodriguez W. Couple-based HIV counseling and testing: a risk reduction intervention for US drug-involved women and their primary male partners. Prevention science : the official journal of the Society for Prevention Research. 2015;16(2):341-51.

5. Shan D, Duan S, Gao J, Yang Y, Ye R, Hu Y, et al. [Analysis of early detection of HIV infections by provider initiated HIV testing and counselling in regions with high HIV/AIDS epidemic in China]. Zhonghua yu fang yi xue za zhi [Chinese journal of preventive medicine]. 2015;49(11):962-6.

6. Hensen B, Baggaley R, Wong VJ, Grabbe KL, Shaffer N, Lo YRJ, et al. Universal voluntary HIV testing in antenatal care settings: a review of the contribution of provider initiated testing \& counselling. Tropical Medicine \& International Health. 2012;17(1):59-70.

7. Ijadunola K, Abiona T, Balogun J, Aderounmu A. Provider-initiated (Opt-out) HIV testing and counselling in a group of university students in Ile-Ife, Nigeria. The European journal of contraception \& reproductive health care : the official journal of the European Society of Contraception. 2011;16(5):387-96.

8. Baisley K, Doyle AM, Changalucha J, Maganja K, Watson-Jones D, Hayes R, et al. Uptake of voluntary counselling and testing among young people participating in an HIV prevention trial: comparison of opt-out and opt-in strategies. PloS one. 2012;7(7):e42108.

9. Topp SM, Chipukuma JM, Chiko MM, Wamulume CS, Bolton-Moore C, Reid SE. Opt-out provider-initiated HIV testing and counselling in primary care outpatient clinics in Zambia. Bulletin of the World Health Organization. 2011;89(5):328-35A.

10. Thakanelo JT, Mulumba-Tshikuka JG, Molefi M, Magafu MG, Matchaba-Hove RB, Masupe T. The burden of opportunisticinfections and associated exposure factors among HIV-patients admitted at a Botswana hospital. 2015.

11. Bernard EJ. BOTSWANA'S DRACONIAN PUBLIC HEALTH BILL APPROVED BY PARLIAMENT, BONELA WILL CHALLENGE IT AS UNCONSTITUTIONAL ONCE PRESIDENT SIGNS INTO LAW (UPDATE 3). HIV justice Network. 2013.

12. Biglan A, Ary D, Wagenaar AC. The value of interrupted timeseries experiments for community intervention research. Prevention science : the official journal of the Society for Prevention Research. 2000;1(1):31-49.

\section{*Mooketsi Molefi}

E-mail: mooketsimolefi@gmail.com 